\title{
1 EL COMPROMISO SOCIAL DE LAS ENFERMERAS
}

| Francisco Megías-Lizancos ${ }^{1}$ |

\section{INTRODUÇÃO}

Quisiera ofrecer mis reflexiones sobre el modo en que las enfermeras pueden desarrollar su responsabilidad y compromiso profesional, tanto en el trabajo diario como más allá, participando en la vida social con personas y grupos que presentan o pueden presentar necesidades de salud; siendo también necesario que en aras al compromiso profesional, participen activamente en las políticas sociales y de salud que los distintos gobiernos quieran emprender o no emprender. Partiendo del hecho de que la enfermera solo puede desarrollar su compromiso social a partir de la conciencia profunda de la superior "bondad" de la profesión enfermera, comenzaremos hablando de una mirada global sobre mismo.

Nuestra sociedad marcha hacia una revolución de la concepción de valores tradicionales. El trabajo, la familia, la religión, el Estado, ya no significan para nosotros lo mismo que para nuestros abuelos. Ante estas transformaciones de valores e ideas dominantes, las enfermeras deben de manifestar respeto, con una actitud positiva, que signifique no solo la aceptación, sino el apoyo profesional donde sea necesario, para el desarrollo de estos valores en la sociedad.

Las enfermeras no pueden estar fuera de los cambios iniciados en la sociedad, ni siquiera les estará permitido mantenerse al margen o a la espera de las decisiones de otros, sino que deben aportar, sin miedos ni sensaciones de inferioridad, el gran potencial humano y de conocimientos que será indispensable para el logro de la meta común. Todo ello tiene que ver con el compromiso. Moliner lo define como "obligación contraída con alguien, contrato, etc... Acuerdo por el que los que lo establecen se comprometen a algo". Según esto, la obligación es contraída por la enfermera, de manera implícita, en una relación contractual con las personas y los grupos sociales, de modo que su compromiso con los mismos emana del propio juramento profesional.
Según Becker "Una persona está comprometida cuando observamos que sigue una línea consecuente de actividad en una serie de situaciones diferentes. La actividad consecuente persiste en el tiempo."

En este sentido la consecuencia tiene que ver entre otras cosas, con atender a las personas en la realidad de su entorno, con sus aspiraciones, en cuanto a calidad de vida, y sus carencias para conseguirla o, lo que es lo mismo, para conseguir las más altas cotas de salud y bienestar. Y la persistencia da también la idea, de la necesidad de perseverar al lado de las personas y de los grupos sociales a lo largo de la vida natural de los mismos.

Desde el inicio de la concepción de la "profesión", hemos visto cómo enfermeras de todo el mundo han estado comprometidas con la misma.

Comprometida fue Florence Nightingale cuando fundó la primera Escuela de Enfermería en 1860, que se siguió con la fundación de diferentes Escuelas por todo el mundo. De aquellas iniciativas y muchos años después, los estudios de Enfermería pasaron a impartirse en las universidades, dotándose así la profesión, de un marco conceptual que daría pie a un compromiso colectivo muy serio, investigando en cuidados y persiguiendo la calidad de los mismos.

Igualmente, es importante que el compromiso se transmita desde el aula, para favorecer un aprendizaje significativo, donde los alumnos construyan conocimiento y competencia profesional, siendo capaces de gestionar adecuadamente sus propias emociones, autoconocimiento y responsabilidad en el reto del cuidado.

En los últimos 30 años la Enfermería ha evolucionado en un marco metodológico que fortalece la profesión desde la perspectiva del compromiso con las personas y con los grupos sociales, para satisfacer sus necesidades.

El trabajo se puede ejercer como pago de una transacción o de un intercambio de equivalentes, pero se puede ejercer también por un sentido del compromiso personal. 
Ambas modalidades no son contradictorias ni incompatibles, pero la segunda añade un matiz cualitativo valioso, un plusvalor. El compromiso personal consolida y refuerza las motivaciones que se puedan tener en la labor ejercida cada día.

En este sentido, quien está comprometido tiene habitualmente una motivación más sólida para cumplir. Se suele guiar por el objetivo a realizar porque toma como guía el contenido mismo de su actividad, no la compensación económica que recibirá por ella.

Esto confiere a la actividad profesional una cualidad humana superior. Y no olvidemos que el compromiso tiene la facilidad de ser contagiado. Personas comprometidas transmiten una forma de actuar comprometida que impulsa al cambio favorable.

Igualmente, el desarrollo del compromiso profesional se lleva a cabo muchas veces, desde actividades no remuneradas, asociadas al voluntariado, $\mathrm{ONG}^{\prime}$ s, etc... La necesidad de estas actividades está en aumento en un momento tan deteriorado desde el punto de vista de la economía.

Adquirir un compromiso supone valorar a los otros y poner en común el principio de beneficencia. Hay que hacer una apuesta por las personas aunque ello suponga ciertos riesgos: sentimiento de falta de capacidad para abordar la situación o aislamiento en el equipo ocasionado por el desvío respecto a la "pauta marcada”.

Sólo el que se compromete cuida. Cuidar es una responsabilidad pública, social, familiar y personal. Cuidar es pensar, no sólo hacer, y tiene una serie de repercusiones positivas en la salud de las mujeres y de los hombres. En palabras de la enfermera $\mathrm{M}^{\mathrm{a}} \mathrm{Con}$ suelo Carballal, cuidar es PRESENCIA; es la presencia comprometida de la enfermera cercana a las personas, las familias y los grupos, y con propósito de continuidad a lo largo del tiempo.

Asimismo, el compromiso desde la gestión debe traducirse en responsabilidad social, protegiendo los valores de la comunidad y de las personas. Los gestores deben comprometerse a gestionar el compromiso de los profesionales y esto solo es posible desde un Sistema Público de Salud.
Muchos profesionales se ven en la controversia de tener en ocasiones, que gestionar su trabajo como marcan los directivos, conscientes de que no es la mejor manera para conseguir los mejores resultados. En estas ocasiones, es aconsejable una negociación conducente a encontrar el equilibrio entre la oferta enfermera que este profesional está dispuesto a llevar a cabo de manera consecuente y comprometida con la población a la que ha de atender, y los objetivos que marca la institución.

La noción de compromiso no debe reducirse exclusivamente, al ámbito profesional y laboral, puesto que se vive en sociedad y toca asumir responsabilidades como ciudadanos.

El compromiso social tiene que ver por tanto con el contexto social y político. La participación de los grupos sociales en el desarrollo de la vida pública y por ende, de las decisiones políticas, es imprescindible para poder conceptualizar los problemas en la vida social y definir los objetivos a alcanzar tanto referidos al bienestar general de las personas como a las situaciones singulares: enfermos mentales, enfermos de SIDA, transeúntes, inmigrantes, parias... Es por ello que habría que trabajar en la corresponsabilidad de la población en la gestión de lo público.

Ahora bien, hay personas que por su situación, tales como los enfermos mentales, los enfermos de SIDA, etc. necesitan de una protección especial. Esto implica que, en el abordaje de las personas con estos problemas, uno de los elementos clave de la rehabilitación o integración social sea prevenirlas de la estigmatización, para lo cual es necesario el compromiso con la persona, con los familiares y con los grupos sociales que le rodean.

Es necesario, a mi entender y para afrontar esas situaciones, promover la reflexión y el debate, proporcionando puntos de encuentro en la plaza, en la plaza pública, superando la corrala, el patio o la intimidad de la casa, a la luz de todos, para que unos y otros puedan profundizar en el conocimiento mutuo y viéndose más iguales para participar en una vida social más democrática.

El compromiso es solidaridad, acercamiento a las personas y constancia. La constancia entendida como el estar, y el estar siempre, en las necesidades, en la ayuda y en definitiva, en el apoyo mutuo. 
